\title{
Usefulness of three-dimensional echocardiography in assessing right ventricular function in patients with primary pulmonary hypertension
}

\author{
Makoto Amaki $^{1}$, Satoshi Nakatani ${ }^{1,2}$, Hideaki Kanzaki ${ }^{1}$, Shingo Kyotani ${ }^{1}$, Norifumi Nakanishi ${ }^{1}$, \\ Chiaki Shigemasa $^{3}$, Ichiro Hisatome ${ }^{4}$ and Masafumi Kitakaze ${ }^{1}$
}

Although right ventricular (RV) function is an important determinant of morbidity and mortality in patients with primary pulmonary hypertension (PPH), there have been no clinically validated quantification methods to date. The first derivative of RV pressure $(\mathrm{d} P / \mathrm{d} t)$ is a good index of contractility, but it depends on preload. $\mathrm{d} P / \mathrm{d} t$ divided by end-diastolic volume (EDV), that is, $\mathrm{d} / \mathrm{d} t / \mathrm{EDV}$, on the other hand, is an index of contractility relatively independent of preload. However, the measurement of accurate RV EDV is difficult because of RV complex geometry. Real-time three-dimensional (3D) echocardiography allows us to measure ventricular volume irrespective of its shape. To investigate the clinical feasibility and significance of 3D echocardiography in evaluating RV function in patients with PPH by measuring RV EDV and dP/dt/EDV, 13 patients with PPH (41 \pm 20 years, four men) underwent echocardiography, a 6-min walk distance (mWD) test and blood sampling within 1 week of invasive hemodynamic measurements. RV $\mathrm{d} P / \mathrm{d} t$ was estimated from a continuous wave Doppler-determined tricuspid regurgitant velocity. RV EDV was measured by both two-dimensional (2D) biplane Simpson method (EDV $2 \mathrm{D})$ and

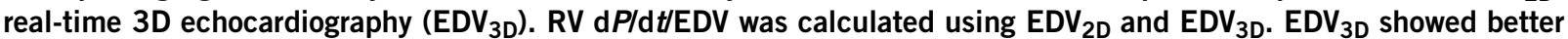
correlations than $\mathrm{EDV}_{2 \mathrm{D}}$ with the invasive and non-invasive parameters of RV function, suggesting the validity of volume measurement by 3D echocardiography. RV $\mathrm{d} P / \mathrm{d} t / \mathrm{EDV}_{3 \mathrm{D}}$ correlated well with disease severity, whereas $\mathrm{d} P / \mathrm{d} t$ and $\mathrm{d} P / \mathrm{d} t / \mathrm{EDV}_{2 \mathrm{D}}$ did not. In patients with PPH, 3D-echocardiography-determined RV dP/dt/EDV and EDV seem to be potential markers of disease severity.

Hypertension Research (2009) 32, 419-422; doi:10.1038/hr.2009.20; published online 27 March 2009

Keywords: primary pulmonary hypertension; right ventricular function; three-dimensional echocardiography

\section{INTRODUCTION}

Primary pulmonary hypertension (PPH) is an uncommon but progressive disease characterized by elevated pulmonary artery pressure with pathological changes in precapillary pulmonary artery. ${ }^{1}$ In the 1990s, treatment with a continuous intravenous infusion of epoprostenol was shown to improve the symptoms and prognosis of $\mathrm{PPH}$. However, prognosis of the disease still remains poor. Right ventricular (RV) function is an important determinant of morbidity and mortality in patients with $\mathrm{PPH}^{2,3}$ Right heart catheterization parameters, such as cardiac index, right atrial pressure and pulmonary artery pressure, correlate well with prognosis of $\mathrm{PPH}$ patients, ${ }^{3,4}$ and are the standard for assessing the severity and prognosis of $\mathrm{PPH}^{2,3}$ However, catheter examination is a high-risk procedure for $\mathrm{PPH}$ patients and therefore is not suitable for repeated assessment. On the other hand, the first derivative of $\mathrm{RV}$ pressure $(\mathrm{d} P / \mathrm{d} t)$, which can be estimated using continuous-wave Doppler echocardiography, is known to be a good index of contractility, but it is preload dependent. ${ }^{5}$ In contrast, $\mathrm{d} P / \mathrm{d} t$ divided by end-diastolic volume (EDV), $\mathrm{d} P / \mathrm{d} t / \mathrm{EDV}$, is an index of contractility that is relatively independent of preload. ${ }^{6}$ It is but not routinely used in the assessment of RV function, because the complexity of RV geometry hampers accurate measurement of RV volume. Real-time three-dimensional (3D) echocardiography allows us to measure RV volume irrespective of its shape. ${ }^{7-9}$

The purpose of this study was to determine the clinical significance of 3D-echocardiography-determined $\mathrm{RV} \mathrm{d} P / \mathrm{d} t / \mathrm{EDV}$ by comparing it with invasive measurements in patients with $\mathrm{PPH}$.

${ }^{1}$ Division of Cardiology, National Cardiovascular Center, Osaka, Japan; ${ }^{2}$ Division of Functional Diagnostics, Department of Health Sciences, Osaka University Graduate School of Medicine, Osaka, Japan; ${ }^{3}$ Division of Regenerative Medicine and Therapeutics, Department of Genetic Medicine and Regenerative Medicine and Therapeutics, Institute of Regenerative Medicine and Biofunction, Tottori University Graduate School of Medical Science, Tottori, Japan and ${ }^{4}$ Division of Molecular Medicine and Therapeutics, Department of Multidisciplinary Internal Medicine, Tottori University Faculty of Medicine, Tottori, Japan

Correspondence: Dr S Nakatani, Division of Functional Diagnostics, Department of Health Sciences, Osaka University Graduate School of Medicine, 1-7 Yamada-oka, Suita, Osaka 565-0871, Japan.

E-mail: nakatani@sahs.med.osaka-u.ac.jp

Received 17 September 2008; revised 16 December 2008; accepted 11 February 2009; published online 27 March 2009 


\section{METHODS}

\section{Patient population}

We studied 20 consecutive patients with PPH who had been referred to our hospital. PPH was diagnosed according to the criteria established by the National Heart, Lung and Blood Institute for the PPH patient registry. ${ }^{4}$

Seven patients were excluded from the analysis for the following reasons. In four patients, the heart size exceeded the pyramidal scan volume of $3 \mathrm{D}$ echocardiography. In three patients, continuous-wave Doppler flow profile was not satisfactory enough to determine $\mathrm{d} P / \mathrm{d} t$. As a result, the study subjects consisted of 13 patients (average age: $42 \pm 16$ years, four men).

\section{Study protocol}

Patients received echocardiography, unencouraged 6-min walk distance $(6 \mathrm{mWD})$ test and blood sampling for brain natriuretic peptide (BNP) within 1 week of right heart catheterization. The study protocol was approved by our ethical committee and informed consent was obtained from each patient.

\section{Hemodynamic studies}

A7 F Goodtec Thermodilution Catheter (Goodman Co., Nagoya, Japan) was used to measure right-heart hemodynamics. Measurements included heart rate, mean right atrial pressure, mean pulmonary arterial pressure (mPAP), pulmonary capillary wedge pressure (PCWP) and mixed venous oxygen saturation $\left(\mathrm{SvO}_{2}\right)$. Cardiac output $(\mathrm{CO})$ was obtained using the calculated Fick method, and cardiac index (CI) was determined. Pulmonary vascular resistance (PVR) was calculated by using the formula $\mathrm{PVR}=80 \times(\mathrm{mPAP}-\mathrm{PCWP}) / \mathrm{CO}$.

\section{Echocardiographic measurements}

Two-dimensional (2D) and real-time 3D echocardiograms were performed using a commercially available ultrasonograph (iE33, Philips Medical System, Best, The Netherlands). Each patient was examined in a supine position. Realtime 3D echocardiographic images were acquired in a transthoracic apical fullvolume mode using a matrix-array transducer $(\mathrm{X} 4,2-4 \mathrm{MHz}$, Philips Medical System). The 3D images were stored in a compact disk for off-line analysis.

\section{D echocardiographic assessment of RV EDV and the right atrial area}

Right ventricular $\mathrm{EDV}_{2 \mathrm{D}}$ was measured using $2 \mathrm{D}$ echocardiography by the modified Simpson method, tracing the endocardium of the right ventricle at four- and two-chamber views at end-diastolic phase. For both apical views, end-diastolic frames were selected as those captured at the peak of the $\mathrm{R}$ wave.

\section{D echocardiographic assessment of RV end-diastolic volume}

Using the full-volume data obtained by $3 \mathrm{D}$ echocardiography, RV EDV $3 \mathrm{D}$ was measured with a commercially available software (3DQ advance QLAB v4.1, Philips Medical System). Care was taken to include the entire RV cavity within the pyramidal scan volume. The $3 \mathrm{D}$ volume dataset was first displayed in three different cross-sections that could be modified interactively. The anatomically correct four- and two-chamber views were displayed simultaneously. Markers were then placed onto the tricuspid annulus and the apex. Using these markers, endocardial contours were traced automatically by the software at end-diastole with the papillary muscles included in the RV cavity. By rotating and scanning the three different cross-sections, manual correction was applied if needed.

\section{Doppler echocardiography}

Right ventricular $\mathrm{d} P / \mathrm{d} t$ was estimated from continuous-wave Doppler-determined tricuspid regurgitant velocity. ${ }^{5}$ The continuous-wave Doppler flow profile of tricuspid regurgitation was obtained with the Doppler beam parallel to the direction of the regurgitant jet, with the aid of color Doppler echocardiography at the apical view. Recordings were carried out at a speed of $100 \mathrm{~mm} \mathrm{~s}^{-1}$. Similar to left-ventricular $\mathrm{d} P / \mathrm{d} t$ estimation using mitral regurgitation, $\mathrm{RV} \mathrm{d} P / \mathrm{d} t$ was calculated using the interval between 1 and $3 \mathrm{~m} \mathrm{~s}^{-1}$ on the tricuspid regurgitation velocity spectrum.
Right-ventricular $\mathrm{d} P / \mathrm{d} t / \mathrm{EDV}$ was calculated using both $\mathrm{EDV}_{2 \mathrm{D}}$ and $\mathrm{EDV}_{3 \mathrm{D}}$. $\mathrm{RV} \mathrm{d} P / \mathrm{d} t, \mathrm{RV}_{\mathrm{EDV}} \mathrm{D}_{2 \mathrm{D}}, \mathrm{RV}_{\mathrm{EDV}} \mathrm{ED}_{3 \mathrm{D}}, \mathrm{RV} \mathrm{d} P / \mathrm{d} t / \mathrm{EDV}_{2 \mathrm{D}}$ and $\mathrm{RV} \mathrm{d} P / \mathrm{d} t / \mathrm{EDV}_{3 \mathrm{D}}$ were compared with conventional prognostic markers of $\mathrm{PPH}$.

\section{Interobserver and intraobserver variability}

To determine the interobserver variability in the $2 \mathrm{D}$ and RT3D evaluations of RV EDV, all measurements were repeated by a second observer, who was blinded to the values obtained by the first observer. Interobserver variability was calculated for each patient as the absolute difference between the two observers, expressed as percentage of their mean. To assess intraobserver variability, all measurements were repeated using the stored images 1 month later by an observer who was blinded to the results of the previous measurements. Intraobserver variability was calculated as the difference between the two measurements, and expressed as percentage of their mean.

\section{Statistical analysis}

All analyses were performed using JMP statistical software (a business unit of SAS, version 5.1.1, SAS Inc., Cary, NC, USA). Data were summarized as mean \pm s.d. for continuous variables and the number of subjects (\%) for categorical variables. For all statistical assessments, $P$-value $<0.05$ was considered statistically significant.

\section{RESULTS}

\section{Patient characteristics}

Baseline demographic features, the plasma BNP levels, 6-mWD results and hemodynamic characteristics of the 13 patients are shown in Table 1. Most of the patients were women, and their New York Heart Association (NYHA) classes were II-III. Continuous intravenous epoprostenolol infusion was given to $39 \%$ of the patients. Bosentan, an orally active dual endothelin-receptor antagonist, was given to $46 \%$, and Beraprost sodium was given to $46 \%$ of the patients. Mean pulmonary artery pressure, measured by catheter examination, ranged from 42 to $74 \mathrm{~mm} \mathrm{Hg}$. CI, measured using the calculated Fick formula,

Table 1 Clinical features, exercise capacity and hemodynamic characteristics

\begin{tabular}{|c|c|}
\hline & Mean \pm s.d. or $n$ \\
\hline Age (years) & $42 \pm 17$ \\
\hline Male gender $(n(\%))$ & $4(27)$ \\
\hline Body surface area $\left(\mathrm{cm}^{2}\right)$ & $1.52 \pm 0.12$ \\
\hline \multicolumn{2}{|l|}{ NYHA (n (\%)) } \\
\hline II & $7(54)$ \\
\hline III & $6(46)$ \\
\hline \multicolumn{2}{|l|}{ Medication (n (\%)) } \\
\hline Continuous epoprostenolol infusion & $5(39)$ \\
\hline Bosentan & $6(46)$ \\
\hline Beraprost sodium & $6(46)$ \\
\hline Furosemide & $7(54)$ \\
\hline BNP (pg per $100 \mathrm{ml}$ ) & $195 \pm 140$ \\
\hline 6-min walk distance $(\mathrm{m})$ & $445 \pm 75$ \\
\hline Mean heart rate (beats per min) & $76.8 \pm 32$ \\
\hline Mean PA pressure $(\mathrm{mm} \mathrm{Hg})$ & $53.2 \pm 10.1$ \\
\hline Mean RA pressure $(\mathrm{mm} \mathrm{Hg})$ & $6.2 \pm 4.4$ \\
\hline PVR (dyne $\times \mathrm{scm}^{-5}$ ) & $1280 \pm 400$ \\
\hline Cardiac index $\left(1 \mathrm{~min}^{-1}\right)$ & $2.0 \pm 0.4$ \\
\hline Mixed venous $\mathrm{O}_{2}$ saturation (\%) & $59.1 \pm 18.3$ \\
\hline
\end{tabular}

Abbreviations: BNP, brain (B-type) natriuretic peptide; NYHA, New York Heart Association functional class; PA, pulmonary artery; RA, right atrial; PVR, pulmonary vascular resistance. 
Table 2 Echocardiographic features

\begin{tabular}{lc}
\hline Variable & \\
\hline $\mathrm{EDV}_{2 D}(\mathrm{ml})$ & $104.4 \pm 32$ \\
$\mathrm{EDV}_{3 D}(\mathrm{ml})$ & $84.7 \pm 23$ \\
$\mathrm{~d} P / \mathrm{d} t\left(\mathrm{~mm} \mathrm{Hg} \mathrm{s}^{-1}\right)$ & $625 \pm 124$ \\
$\mathrm{~d} / \mathrm{d} t / \mathrm{EDV}_{2 \mathrm{D}}\left(\mathrm{mm} \mathrm{Hgs} \mathrm{ml}^{-1}\right)$ & $6.6 \pm 2.8$ \\
$\mathrm{~d} P / \mathrm{d} t / \mathrm{EDV}_{3 D}\left(\mathrm{~mm} \mathrm{Hg} \mathrm{ml}^{-1}\right)$ & $7.8 \pm 1.9$ \\
Tricuspid regurgitation grade & $2.3 \pm 1.0$ \\
(RV-RA) pressure gradient $(\mathrm{mm} \mathrm{Hg})$ & $78.3 \pm 37$
\end{tabular}

Abbreviations: $E D V_{2 D}$, end-diastolic volume measured by two-dimensional echocardiography; $E V_{3 D}$, end-diastolic volume measured by three-dimensional echocardiography; RV-RA: right ventriculo-atrial.

Table 3 Correlation coefficient

\begin{tabular}{lccccc}
\hline & $\mathrm{Cl}$ & $m R A P$ & $\mathrm{SvO}_{2}$ & $B N P$ & $6 m W D$ \\
\hline $\mathrm{EDV}_{2 \mathrm{D}}$ & $\mathrm{NS}$ & $0.70^{* *}$ & $\mathrm{NS}$ & $0.58^{*}$ & $\mathrm{NS}$ \\
$\mathrm{EDV}_{3 \mathrm{D}}$ & $-0.69^{* *}$ & $0.65^{*}$ & $-0.70^{* *}$ & $\mathrm{NS}$ & $\mathrm{NS}$ \\
$\mathrm{d} P / \mathrm{d} t$ & $\mathrm{NS}$ & $\mathrm{NS}$ & $\mathrm{NS}$ & $\mathrm{NS}$ & $\mathrm{NS}$ \\
$\mathrm{d} P / \mathrm{d} t / \mathrm{EDV}_{2 \mathrm{D}}$ & $\mathrm{NS}$ & $\mathrm{NS}$ & $\mathrm{NS}$ & $\mathrm{NS}$ & $\mathrm{NS}$ \\
$\mathrm{d} P / \mathrm{d} t / \mathrm{EDV}_{3 \mathrm{D}}$ & $0.60^{*}$ & $-0.55^{*}$ & $\mathrm{NS}$ & $-0.61^{*}$ & $\mathrm{NS}$ \\
\hline
\end{tabular}

Abbreviations: $6 \mathrm{mWD}, 6$-min walk distance; $\mathrm{Cl}$, cardiac index; $\mathrm{EDV}_{2 \mathrm{D}}$, end-diastolic volume measured by two-dimensional echocardiography; EDV 3 , end-diastolic volume measured by three-dimensional echocardiography; mRAP, mean right atrial pressure; $\mathrm{SvO}_{2}$, mixed venous three-dimensional oxygen saturation.
${ }^{*} P<0.05,{ }^{*} P<0.01$

ranged from 1.4 to $2.71 / \mathrm{min}$. The distance of 6 -min walk was shorter in patients with class III, compared with those with NYHA class II $(370 \pm 28$ vs $491 \pm 21 \mathrm{~m}, P<0.01)$. CI was smaller and PVR and BNP were larger in patients with NYHA class III, but the difference was not significant. Echocardiographic measurements are shown in Table 2. EDV measured by $2 \mathrm{D}$ echocardiography was significantly larger than that measured by $3 \mathrm{D}$ echocardiography $(P<0.05)$.

\section{Relationship between echocardiographic parameters and hemodynamics}

The correlation coefficients between echocardiographic measurements and hemodynamics, both plasma BNP levels and $6 \mathrm{mWD}$ are listed in Table 3. $\mathrm{EDV}_{3 \mathrm{D}}$ showed better correlations with the hemodynamics compared with $\mathrm{EDV}_{2 \mathrm{D}}$. $\mathrm{EDV}_{2 \mathrm{D}}$ had significant correlations with mean RAP and plasma BNP levels, but not with $\mathrm{CI}$ and $\mathrm{SvO}_{2}$. RV $\mathrm{d} P / \mathrm{d} t$ and $\mathrm{d} P / \mathrm{d} t / \mathrm{EDV}_{2 \mathrm{D}}$ were not correlated with any of those measurements. However, RV $\mathrm{d} P / \mathrm{d} t / \mathrm{EDV}_{3 \mathrm{D}}$ showed a good correlation with the invasive and the non-invasive parameters of RV function (Table 3 ).

\section{Reproducibility}

The interobserver variability was $25 \pm 13 \%$ of the measured $\mathrm{EDV}_{2 \mathrm{D}}$, ranging between 5 and $55 \%$ between patients, and $11 \pm 8 \%$ of the measured $\mathrm{EDV}_{3 \mathrm{D}}$, ranging between 3 and $23 \%(P<0.05$ between techniques). The intraobserver variability was $21 \pm 8 \%$ of the measured $\mathrm{EDV}_{2 \mathrm{D}}$, ranging between 11 and $41 \%$ between patients, and $9 \pm 5 \%$ of the measured $\mathrm{EDV}_{3 \mathrm{D}}$, ranging between 3 and $19 \%$ between patients $(P<0.05$ between techniques).

\section{DISCUSSION}

In this study, we found 3D-echocardiography-derived RV EDV and $\mathrm{d} P / \mathrm{d} t / \mathrm{EDV}$ showed a good correlation with indices of the cardiac function compared with those determined by $2 \mathrm{D}$ echocardiography.

\section{Assessment of severity and the prognosis of PPH patients} with conventional echocardiographic indices

Earlier investigators showed the clinical significance of 2D echocardiographic parameters in patients with $\mathrm{PPH}$. Increasing severity of pericardial effusion was found to be associated with prognosis of PPH. ${ }^{10}$ Another study showed pericardial effusion and indexed RA were independently associated with the mortality. ${ }^{11}$ However, these parameters simply reflect the end stage of RV failure. It is important to assess the disease status and the effect of the therapy in the management of PPH. Therefore, quantitative analysis of RV function is necessary in the clinical setting. Our findings shed light on the possibility of determining the severity of $\mathrm{PPH}$ non-invasively.

\section{Index of RV systolic function}

There have been several methods for assessing RV function. The conductance catheter is a frequently used instrument to assess RV function. ${ }^{12,13}$ Conductance-derived pressure-volume data are preloadindependent measurements of RV contractile function. However, conductance catheterization is invasive and not cost-effective. Therefore, they are predominantly used as a research tool for assessment of ventricular function. Attempt has been made to measure RV function by echocardiography, but the simple M-mode or $2 \mathrm{D}$ echocardiographic indices cannot be reliably applied for assessing the RV function because of RV complex geometry. ${ }^{14}$ Other non-invasive methods, such as MRI, can be used accurately to measure enddiastolic and end-systolic volumes and calculate the ejection fraction, ${ }^{15,16}$ but these methods are time consuming and cannot be performed at the bedside.

Left-ventricular $\mathrm{d} P / \mathrm{d} t$ has been well established as an index of contractility and is known to correlate well with the prognosis of leftventricular dysfunction. ${ }^{17}$ There have been few studies on Dopplerderived $\mathrm{RV} \mathrm{d} P / \mathrm{d} t$. Anconina et al. ${ }^{18}$ measured the mean rate of right ventriculo-atrial pressure gradient and showed good correlation with invasively determined maximal $\mathrm{d} P / \mathrm{d} t$. We have previously reported that non-invasive measurement of RV peak-positive $\mathrm{d} P / \mathrm{d} t$ by echocardiography correlated well with that derived by catheterization irrespective of the level of right atrial pressure. ${ }^{19}$ However, $\mathrm{d} P / \mathrm{d} t$ is dependent on preload, ${ }^{5}$ and may overestimate the contractility in RV dilatation accompanied by $\mathrm{PPH}$.

\section{Measuring 3D-echocardiography-derived RV dP/dt/EDV}

In this study, we analyzed RV $\mathrm{d} P / \mathrm{d} t$ divided by RV EDV obtained by 3D echocardiography. As RV EDV has been shown to be a marker of preload, ${ }^{20,21} \mathrm{RV} \mathrm{d} P / \mathrm{d} t$ divided by RV EDV should be a marker of preload-independent RV function. We have shown that $\mathrm{RV} \mathrm{d} P / \mathrm{d} t /$ $\mathrm{EDV}_{3 \mathrm{D}}$ correlated well with both invasively and non-invasively derived RV function indices.

Although there are many parameters that relate to the severity and prognosis of $\mathrm{PPH}$, no single parameter can be the gold standard. We used invasive measurements as the next best standard and investigated the correlations. The correlation coefficients were not so high, but we believe that $\mathrm{RV} \mathrm{d} P / \mathrm{d} t / \mathrm{EDV}_{3 \mathrm{D}}$ was still clinically useful because no other parameters were good enough to assess the severity of the disease.

\section{Study limitations}

Measuring RV volume by 3D echocardiography is challenging in the severely enlarged RV, especially in patients in the end stage. In our study, we could not measure RV volume in 4 out of 20 patients by 3D echocardiography, because the RV size exceeded the scan volume. It is a major limitation of this study. The latest version of the $3 \mathrm{D}$ 
ultrasound equipment provides us the wider scan area, which may increase the clinical applicability.

$\mathrm{d} P / \mathrm{d} t$ is also affected by afterload. However, in patients with $\mathrm{PPH}$, pulmonary artery pressure is elevated, and the timing of the opening of pulmonary valve is delayed. Therefore, the influence of afterload can be neglected.

Medical therapy also could have affected the result. However, the number of patients with oral medication or with intravenous epoprostenolol infusion was too small to investigate the effect.

In this study, all patients had echocardiography and 6-mWD test within 1 week of catheterization. In addition to the scarcity of PPH itself, this strict criterion was also partly the reason why the number of the patients was small.

Our study population consisted of rather severe PPH patients. It is a limitation of this study that we did not have patients with mild-tomoderate PPH among our study subjects. We believe that our method is applicable even to those with milder disease. It is warranted to conduct larger trials to extend these findings to patients with a different stage of disease.

\section{Clinical implications}

By using our index, we could estimate the catheterization-derived RV function in patients with $\mathrm{PPH}$ non-invasively. It is useful in a setting where the patient condition is unstable and the catheter examination is extremely dangerous. It is also useful when a new drug is administered and the catheter-derived index is needed for repeated assessment of the drug effect.

\section{CONCLUSION}

In patients with $\mathrm{PPH}, 3 \mathrm{D}$-echocardiography-determined RV EDV and $\mathrm{d} P / \mathrm{d} t / \mathrm{EDV}$ correlated well with prognostic markers of $\mathrm{PPH}$, including $\mathrm{CI}$, mean right atrial pressure and $\mathrm{BNP}$. 3D-echocardiography-determined RV $\mathrm{d} P / \mathrm{d} t / \mathrm{EDV}$ seems to be a potential marker of disease severity, and may be useful in assessing therapeutic effects and the prognosis.

\section{CONFLICT OF INTEREST}

The authors declare no conflict of interest.

1 Runo JR, Loyd JE. Primary pulmonary hypertension. Lancet 2003; 361: 1533-1544.

2 Sandoval J, Bauerle O, Palomar A, Gomez A, Martinez-Guerra ML, Beltran M, Guerrero $M L$. Survival in primary pulmonary hypertension. Validation of a prognostic equation. Circulation 1994; 89: 1733-1744

3 D'Alonzo GE, Barst RJ, Ayres SM, Bergofsky EH, Brundage BH, Detre KM, Fishman AP, Goldring RM, Groves BM, Kernis JT, Levy PS, Pietra GG, Reid LM, Reeves JT, Rich S,
Vreim CE, Williams GW, Wu M. Survival in patients with primary pulmonary hypertension. Results from a national prospective registry. Ann Intern Med 1991; 115: 343-349.

4 Rich S, Dantzker DR, Ayres SM, Bergofsky EH, Brundage BH, Detre KM, Fishman AP, Goldring RM, Groves BM, Koerner SK, Levy PC, Reid LM, Vreim CE, Williams GW. Primary pulmonary hypertension. A national prospective study. Ann Intern Med 1987; 107: 216-223.

5 Imanishi T, Nakatani S, Yamada S, Nakanishi N, Beppu S, Nagata S, Miyatake K. Validation of continuous wave Doppler-determined right ventricular peak positive and negative dP/dt: effect of right atrial pressure on measurement. J Am Coll Cardiol 1994; 23: $1638-1643$.

6 Little WC. The left ventricular $\mathrm{dP} / \mathrm{dtmax}$-end-diastolic volume relation in closed-chest dogs. Circ Res 1985; 56: 808-815.

7 Linker DT, Moritz WE, Pearlman AS. A new three-dimensional echocardiographic method of right ventricular volume measurement: in vitro validation. J Am Coll Cardiol 1986; 8: 101-106.

8 Shiota T, Jones M, Chikada M, Fleishman CE, Castellucci JB, Cotter B, DeMaria AN, von Ramm OT, Kisslo J, Ryan T, Sahn DJ. Real-time three-dimensional echocardiography for determining right ventricular stroke volume in an animal model of chronic right ventricular volume overload. Circulation 1998; 97: 1897-1900.

9 Dorosz JL, Bolson EL, Waiss MS, Sheehan FH. Three-dimensional visual guidance improves the accuracy of calculating right ventricular volume with two-dimensional echocardiography. J Am Soc Echocardiogr 2003; 16: 675-681.

10 Eysmann SB, Palevsky HI, Reichek N, Hackney K, Douglas PS. Two-dimensional and Doppler-echocardiographic and cardiac catheterization correlates of survival in primary pulmonary hypertension. Circulation 1989; 80: 353-360.

11 Raymond RJ, Hinderliter AL, Willis PW, Ralph D, Caldwell EJ, Williams W, Ettinger NA, Hill NS, Summer WR, de Boisblanc B, Schwartz T, Koch G, Clayton LM, Jobsis MM, Crow JW, Long W. Echocardiographic predictors of adverse outcomes in primary pulmonary hypertension. J Am Coll Cardiol 2002; 39: 1214-1219.

12 Segers $P$, Leather HA, Verdonck P, Sun YY, Wouters PF. Preload-adjusted maximal power of right ventricle: contribution of end-systolic P-V relation intercept. Am J Physiol Heart Circ Physiol 2002; 283: H1681-H1687.

13 Brown KA, Ditchey RV. Human right ventricular end-systolic pressure-volume relation defined by maximal elastance. Circulation 1988; 78: 81-91.

14 Levine RA, Gibson TC, Aretz T, Gillam LD, Guyer DE, King ME, Weyman AE. Echocardiographic measurement of right ventricular volume. Circulation 1984; 69: 497-505.

15 Helbing WA, Bosch HG, Maliepaard C, Rebergen SA, van der Geest RJ, Hansen B, Ottenkamp J, Reiber JH, de Roos A. Comparison of echocardiographic methods with magnetic resonance imaging for assessment of right ventricular function in children. Am J Cardiol 1995; 76: 589-594.

16 Vogel M, Gutberlet M, Dittrich S, Hosten N, Lange PE. Comparison of transthoracic three-dimensional echocardiography with magnetic resonance imaging in the assessment of right ventricular volume and mass. Heart 1997; 78: 127-130.

17 Kolias TJ, Aaronson KD, Armstrong WF. Doppler-derived dP/dt and -dP/dt predict survival in congestive heart failure. J Am Coll Cardiol 2000; 36: 1594-1599.

18 Anconina J, Danchin N, Selton-Suty C, Isaaz K, Juilliere Y, Buffet P, Edel F, Cherrier F. Noninvasive estimation of right ventricular $\mathrm{dP} / \mathrm{dt}$ in patients with tricuspid valve regurgitation. Am J Cardiol 1993; 71: 1495-1497.

19 Kanzaki H, Nakatani S, Kawada T, Yamagishi M, Sunagawa K, Miyatake K. Right ventricular $\mathrm{dP} / \mathrm{dt} / \mathrm{P}(\max )$, not $\mathrm{dP} / \mathrm{dt}(\max )$, noninvasively derived from tricuspid regurgitation velocity is a useful index of right ventricular contractility. J Am Soc Echocardiogr 2002; 15: 136-142.

20 Siniscalchi A, Pavesi M, Piraccini E, De Pietri L, Braglia V, Di Benedetto F, Lauro A, Spedicato S, Dante A, Pinna AD, Faenza S. Right ventricular end-diastolic volume index as a predictor of preload status in patients with low right ventricular ejection fraction during orthotopic liver transplantation. Transplant Proc 2005; 37: 2541-2543.

21 Durham R, Neunaber K, Vogler G, Shapiro M, Mazuski J. Right ventricular end-diastolic volume as a measure of preload. J Trauma 1995; 39: 218-223 (discussion 223-4). 